\title{
Piezoelectric Micropump Driving Module With Programmable Slew-Rate and Dead-Time
}

\author{
Matej Možek, Borut Pečar, Drago Resnik and Danilo Vrtačnik
}

University of Ljubljana, Faculty of Electrical Engineering, Laboratory of Microsensor Structures and Electronics (LMSE), Ljubljana, Slovenia

\begin{abstract}
High efficiency piezoelectric micropump driving module with programmable slew-rate and dead-time has been designed, implemented and characterized for driving custom made piezoelectric micropumps. Developed driver enables independent setting of several rectangular output signal parameters, such as frequency, positive and negative amplitudes, slew-rates, dead time, and modes of operation (pump/valve).

Implemented driver can achieve amplitudes up to $250 \mathrm{VPP}$ on a frequency range from DC to $1 \mathrm{kHz}$, slew-rate up to $18 \mathrm{~V} / \mu \mathrm{s}$ at maximum power consumption 1.6W (180 mA @ 9V). In comparison with our previous driver with RC charge/discharge signal shape, presented version increases air flow capability of micropumps from $1.6 \mathrm{sccm}$ to $4.2 \mathrm{sccm}$. It enables driving of $200 \mu \mathrm{m}$ thick PZT actuators with $12 \mathrm{nF}$ capacitance.
\end{abstract}

Keywords: Piezoelectric micropump; driving module; slew-rate; dead-time

\section{Krmilni modul piezoelektričnih mikročrpalk z nastavljivo hitrostjo spremembe in mrtvim časom krmilnega signala}

Izvleček: $\vee$ prispevku so predstavljeni razvoj, izvedba in meritve krmilnega modula piezoelektričnih mikročrpalk z nastavljivo hitrostjo spremembe in mrtvim časom krmilnega signala. Predstavljeni krmilni modul omogoča neodvisno nastavljanje nekaterih parametrov pravokotnega krmilnega signala kot npr.: frekvenca, pozitivna in negativna amplituda napetosti, hitrost dvižne in upadne spremembe, mrtvi čas in način delovanja (črpalni/ventilski).

Izdelani krmilni modul omogoča nastavljanje napetosti do 250 VPP na frekvenčnem področju do 1 kHz, pri hitrosti spremembe signala do 18V/us pri največji porabi 1.6 W (180 mA @9 V). V primerjavi s preteklimi izvedbami krmilnega modula, s kvazi-pravokotno obliko krmilnega signala, ki poustvarja RC polnjenje/praznjenje, smo povečali pretok mikročrpalk iz 1.6 sccm na 4.2 sccm. Izdelani modul omogoča krmiljenje PZT aktuatorja debelin do $200 \mu \mathrm{m}$ in kapacitivnosti do 12 nF.

Ključne besede: piezoelektrična mikročrpalka; krmilni modul; hitrost spremembe krmilnega signala; mrtvi čas krmilnega signala.

*Corresponding Author's e-mail: matej.mozek@fe.uni-lj.si

\section{Introduction}

Piezoelectric micropumps are often used in advanced microfluidic applications where accurate pressure, flow control and monitoring are required. In applications where small flow rate of $\mathrm{ml} / \mathrm{min}$ range and lower is needed, they often represent the most appropriate solution due to their small size and low power consumption. In order to optimize the micropump flow rate and backpressure performance, piezoelectric actuator driving signal has to have appropriate signal shape, ampli- tude and frequency. Available drivers are often either large in size and therefore inappropriate for portable applications [1] or are optimized for driving a specific type of piezoelectric micropump. Most of them feature only a rectangular driving signal with fixed slew rate [2] and limited signal flexibility. Some drivers [3] offer energy recuperation, but they don't employ grounding one of micropump electrodes, which is prerequisite in medical applications. In our previous work [4] a three channel, high voltage analog linear amplifier was de- 
veloped. Though this amplifier enables a detailed insight into micropump operation by covering different pump excitation signals, supplied by an arbitrary function generator, it is not size optimized. Recently [5], we implemented a miniature, transformerless version of a piezoelectric micropump driving module. It features two mutually exclusive switched mode power supply (SMPS) boost converters, with piezoelectric micropump actuator shared as a common output capacitor. This module offers synthesis of standard rectangular-like driving signal, which resembled an RC network charging/discharging through the piezoelectric micropump. Though such output signal shape is far from ideal, it is still suitable for cost sensitive applications. Analyzed results have shown a significant discrepancy in positive and negative driving amplitude, which has to be individually adjusted to particular type of piezoelectric actuator. To address these drawbacks, we present a novel, cost-effective, version of a miniature high voltage piezoelectric micropump driving module, which generates a true rectangular micropump driving signal with independently settable positive and negative driving signal amplitudes, slew-rate, dead-time and frequency.

In order to achieve these functionalities, a simplified high-voltage driving stage was designed. Usual approach is to design a D-class amplifier, with some type of high-side MOSFET driver (e.g. IR2113), which would enable driving with arbitrary shape of signals. On the other hand, it would require several additional components, which would compromise our low-cost approach. In our previous work [6] we have shown, that the most appropriate driving signal shape is square wave with settable frequency, duty cycle, both amplitudes and both slew rates. Low value of both slew rates yield a more trapezoid-like driving signal, which results in lower power consumption, but with a reduced flowrate compared to steeper slew rate signal. In order to reduce overall driving module cost, the micropump high-voltage switching stage was designed using optocouplers, which significantly simplify the design, due to lack of a dedicated level-shifter stage for high-side switch and bootstrapping capacitor, found in high-side driver components.

\section{Microcylinder pump}

Recently presented microcylinder pump [7], was selected for a driver evaluation. Instead of employing checkvalves, it operates on a principle of active sequential expansion (opening) and compression (closing) of the centrally placed inlet cylindrical rectifying element and outlet throttle rectifying element. Micropump expansion and compression are performed by an actuated glass membrane that is loosely attached via a resilient elastomer to the top of the supporting glass. Exploded view of a typical thermoplastic (TP) microcylinder pump structure with constituent materials and corresponding bonding processes is shown in Fig. 1.

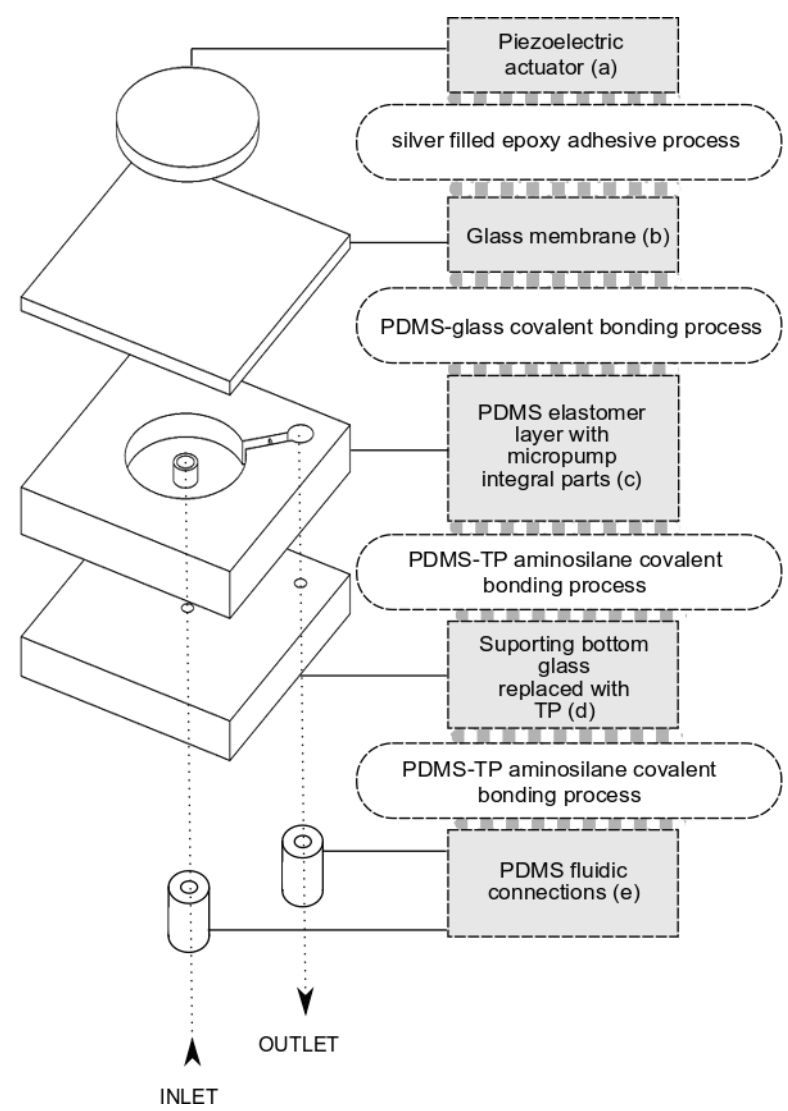

Figure 1: Exploded view of a typical TP microcylinder pump structure with constituent materials and corresponding bonding processes.

The TP microcylinder pump comprises polydimethylsiloxane (PDMS) elastomer layer with molded micropump chamber, fluidic microchannel and rectifying elements (Fig. 1 c). Additionally, two through-holes are punched into an elastomer, one into the center of the micropump chamber and the other one at the end of the channel. PDMS elastomer layer (Fig. $1 \mathrm{c}$ ) and PDMS fluidic connections (Fig. 7 e) are covalently bonded to the supporting TP substrate (Fig. $1 \mathrm{~d}$ ) by employing developed amine-PDMS linker bonding process. One inlet and one outlet fluid port is drilled through a supporting TP substrate that supply and drain the fluid into and out of the pump. The micropump chamber and the microchannel are sealed with a thin glass membrane (Fig. 1 b) by employing oxygen plasma PDMS-glass covalent bonding process. Piezoelectric actuator (Fig 1 a) is positioned in the axis of a micropump chamber, coupled rigidly to the micropump membrane through silver filled epoxy adhesive (EPO-TEK EE129-4, Billerica, MA, USA). 


\section{Module operation}

High voltage power supply section of the investigated circuit is designed around two independent boost SMPS power supplies, which provide micropump positive and negative driving voltage (Figure 1). Lower boost converter, comprised of inductance $L 2$, transistor M2, diode D3 and capacitor C3, provides a source of negative micropump driving voltage, while the upper boost converter (comprised of inductance L1, transistor M1, diode D1 and capacitor C1) provides a source of positive micropump driving voltage. Each SMPS features a resistor divider feedback, which enables independent monitoring of both power supply voltage levels. Both SMPS converters are driven using pulse-width modulation (PWM) signal (see Figure 1, sources V1 and V2) with base frequency $32 \mathrm{kHz}$ in range from $10 \%$ do $90 \%$. Depending on duty cycle setting, both SMPS converters can deliver output voltage in range from \pm 10 $V$ to $\pm 150 \mathrm{~V}$. Our previous designs did not allow independent setting of power supply voltage level, therefore the half period amplitude symmetry could only be achieved by adjusting the duty cycle of an individual switching half-cycle.

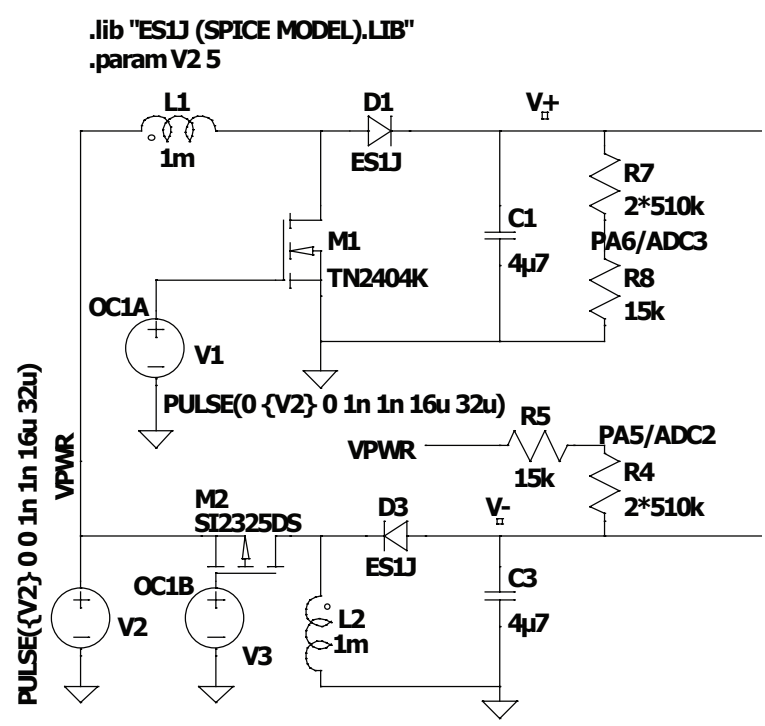

Figure 2: High-voltage part of the driver.

Both positive and negative supply voltages (Figure $1, \mathrm{~V}^{+}$ and $\mathrm{V}$ ) are connected to the micropump via two Darlington output high-voltage optocouplers TLP187 (Figure 2, circuit U1 and U2). Using such setup, frequency, duty cycle and slew-rate for front and rear micropump driving signal edge can be independently set. Slew rates can be digitally set using several microcontroller outputs, which effectively form a simple digital-toanalog converter. In Figure 2, only resistors $\mathrm{SR}_{1}$ and $\mathrm{SR}_{2}$ are shown for simplicity.
In order to generate an alternating rectangular-like excitation signal, positive ( $\mathrm{V}+$ ) and negative ( $\mathrm{V}$-) power supply are switched exclusively by driving signals $V 6$ and V7. Both driving signals feature an obligatory, programmable dead time gap, which is downwards limited by optocoupler turn-off-time ( $80 \mu$ s for TLP187).

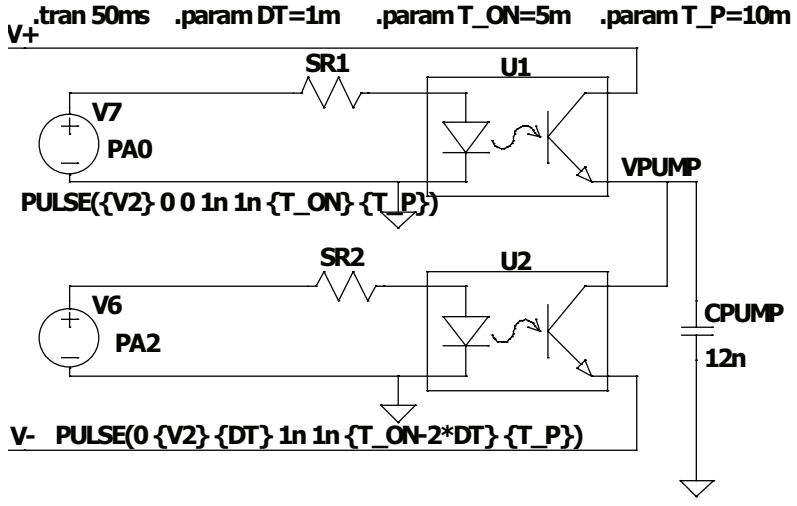

Figure 3: Excitation part of the driver.

\section{Circuit simulations}

Initial simulations of above described circuit were performed in LTSpice XVII [8]. In presented case, measured capacitance of piezoelectric (PZT) actuator $C_{0}$ was 12 $\mathrm{nF}$, while the microcylinder pump excitation frequency was set at $100 \mathrm{~Hz}$ with $50 \%$ symmetry. Switching frequencies of both power supplies were set at $32 \mathrm{kHz}$ and the PZT actuator driving voltage was recorded. Transient analysis of circuit, presented in Figure 3, was simulated for first $50 \mathrm{~ms}$. Simulation results of micropump driving voltage rise at $100 \mathrm{~Hz}$ are shown in Figure 4 .

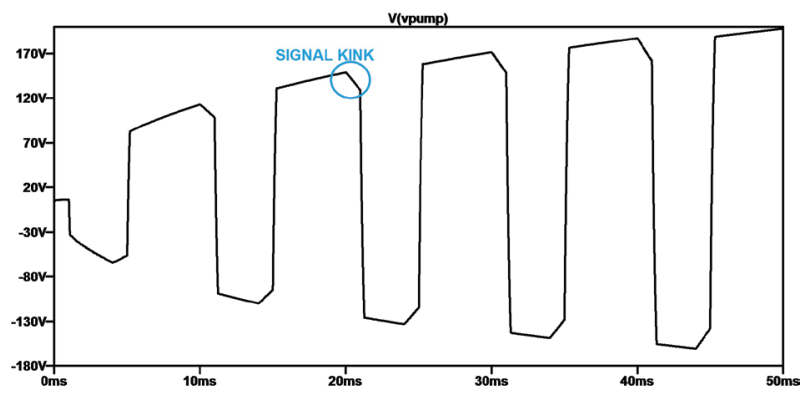

Figure 4: Piezoelectric micropump driving voltage build-up after first $50 \mathrm{~ms}$ of operation.

Simulation parameters, dead time (DT), positive halfcycle (T_ON) and period (T_P) are listed on the top of schematic in Figure 2.

Figure 3 shows a signal kink in square wave signal edge transition, which originates from dead-time, when no 
optocoupler is driven and the micropump piezoelectric actuator is discharged. Excitation of two optocouplers was provided by two phase-exclusive signals (see Figure 4, V6 - dashed line and V7 - solid line) with dead time (DT) of $1 \mathrm{~ms}$, on-time T_ON of $5 \mathrm{~ms}$ and a period T_P of $10 \mathrm{~ms}$ were applied in simulation (see top of Figure 3).

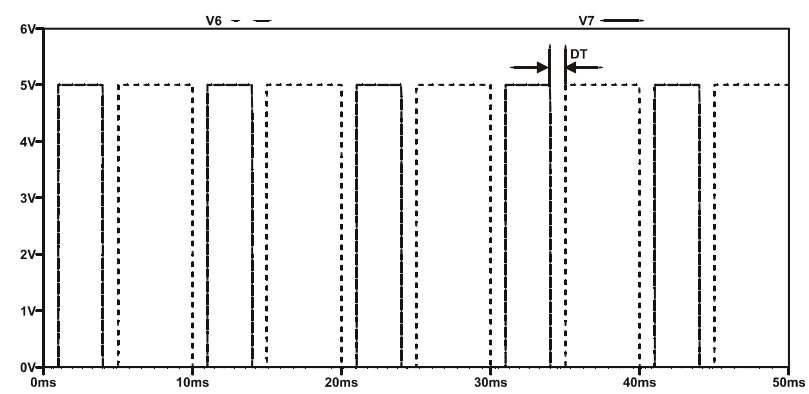

Figure 5: Optocoupler diode driving voltage after first $50 \mathrm{~ms}$ of operation.

Micropump switching period is divided into four states as follows: Active positive voltage driving state (solid line, Figure 5), during which positive SMPS power supply $\left(\mathrm{V}^{+}\right.$on Figure 2$)$ is connected to the micropump using optocoupler U1 (Figure 3), followed by a positive dead time state, where both optocouplers (U1, U2 in Figure 3) are turned off, superseded by a active negative driving state (dashed line, Figure 5), during which negative SMPS power supply ( $V^{-}$, Figure 2 ) is connected to the micropump using optocoupler U2 (Figure 3), and finalized by a negative dead time state, where both optocouplers (U1, U2) are switched off. Splitting the micropump switching period into four independent states gives maximum control over micropump driving signal properties and module power consumption.

Increasing the value of optocoupler base resistors (SR1, SR2 in Figure 3) results in lower micropump driving signal slew-rates, which enables the selection between high-flow performance with high slew-rate, and low flow-performance mode with low slew-rate. Although a single resistor (SR1, SR2) is shown in Figure 3 for clarity, controlling signals V6 and V7 can be fed to the optocouplers via a network of resistors, connected to a multiplexed power source.

Multiplexing power supply via different base resistors enables seamless interchanging between performance modes and different signal shapes: When setting both slew-rates low (a single, high value resistor is fed to base), a sinewave-flanked signal (sinewave signal with time-extended flat extrema) can be obtained. Setting both slew-rates high by turning on multiple resistors results in a square wave signal. Setting rising edge slew rate high, and falling edge low results in the sinewave rectangular signal (SRS signal).

\section{Module control}

Micropump control is based on a cost-effective 8-bit microcontroller, an ATMEL Tiny 104 in a 14-pin SOT-23 package [9].

Selected microcontroller features a single 8-bit timer (TMR0), which is configured to count using $8 \mathrm{MHz}$ internal clock (no prescaler). Counter overflow interrupt is used for transitioning between active and deadtime stages by implementing a state-machine, which preloads next timer-expiration period based on corresponding stage duration. TMRO state machine can also be configured in the "valve mode", in which either a constant positive or negative voltage is fed to the micropump. Microcontroller PWM unit is configured in "fast" (phase non-aligned) mode, with two output compare registers (OCROA/OCROB), running at 31.25 $\mathrm{kHz}$ with 8-bit resolution. PWM outputs (OCOA/OCOB), whose value results from comparison between OCR0x and TMRO value, are connected to corresponding SMPS MOSFET transistor (M1, M2 Figure 2). Both PWM outputs operate in free-running mode. Each SMPS output is fed back to the corresponding microcontroller analog-to-digital converter input (ADC2/ADC3, Figure 2). An analog-to-digital converter interrupt is triggered by TMRO interrupt routine only during positive and negative dead-time switching phase. During positive dead-time state, ADC2 is monitored, and the value of OCROA is altered accordingly. During negative deadtime state, ADC3 is sampled, and the value of OCROB is altered. Microcontroller UART receiver was used to set all micropump driving signal settings: frequency, positive and negative dead time, amplitudes, slew-rates and mode of operation (pump/valve). In order to minimize microcontroller calculations, an Excel VBA based script was developed. This script translates humanreadable parameters such as frequency and dead time to TMRO state-machine expiration periods, determines slew-rate resistor multiplexing state and configures the mode of module operation.

\section{Initial prototype}

In order to evaluate simulated circuit, initial prototype based on $\mathrm{V}_{\mathrm{PWR}}=5 \mathrm{~V}$ power supply, as shown in Figure 6, was designed and implemented.

Switching optocouplers PC817 (U1, U2 in Figure 3), which were used during simulations, were replaced with high-voltage, Darlington output type (Toshiba TLP187), due to better switching characteristics and high-current transfer ratio, which allows higher slew rates. Large (100 $\mu \mathrm{F} / 100 \mathrm{~V})$ rectifying capacitors $(\mathrm{C} 1, \mathrm{C3}$ 


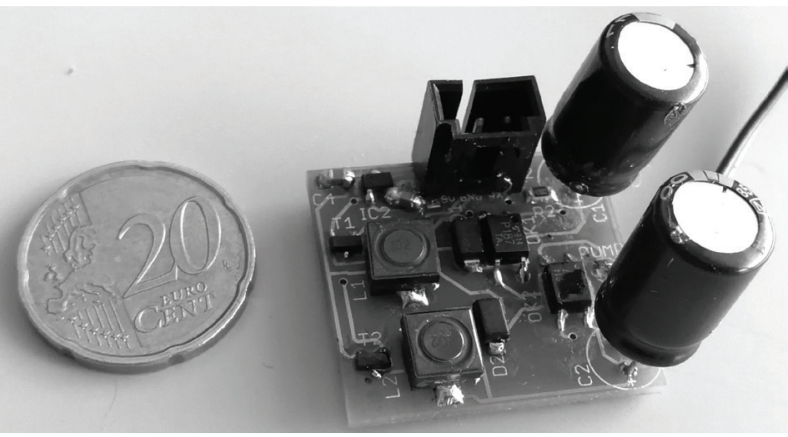

Figure 6: Initial driver prototype.

in Figure 2) were initially used to minimize the power supply ripple.

A LeCroy WaveRunner 64 Xi oscilloscope was connected to initial prototype in Figure 6. Tested module was driving the microcylinder micropump with PZT capacitance $12 \mathrm{nF}$. Both micropump signal driving extremes were tested:

1.) A "full drive" condition, with dead time set to DT $=200 \mu \mathrm{s}$, which sets driving micropump voltage almost for entire corresponding half-cycle (Figure 4).

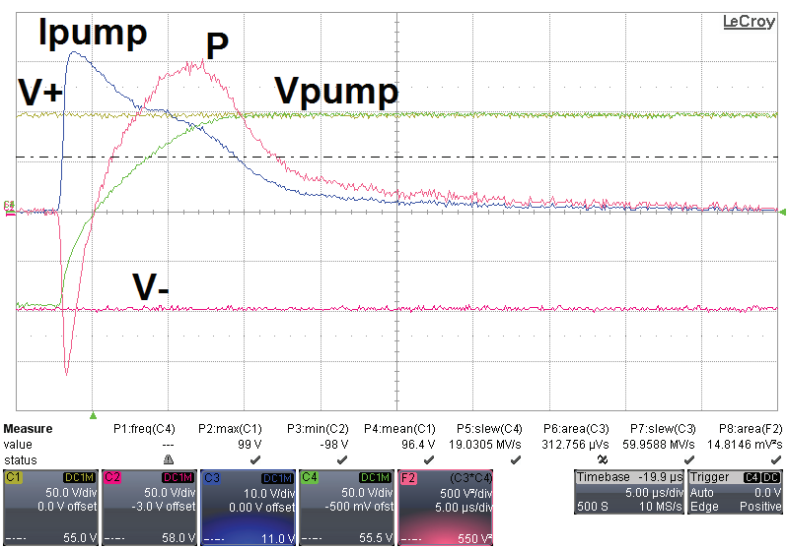

Figure 7: Initial prototype "full drive" front edge.

Figure 7 is showing the micropump "full drive" output signal front-edge detail at $100 \mathrm{~Hz}$ and $100 \mathrm{~V}$ amplitude. Actual achieved micropump power supply amplitudes was $98 \mathrm{~V}$. The detail in Figure 7 also shows the micropump current (trace $\mathrm{I}_{\mathrm{Pump}}$ ), measured as a voltage drop on a current-to-voltage op-amp circuit with a $100 \Omega$ resistor. Micropump current achieves its peak value of $302 \mathrm{~mA}$ immediately after start of transition and then slowly decays towards zero in approximately $35 \mu \mathrm{s}$. A specific kink in the current decay is caused by Darlington transistor output. Area of current oscilloscope channel (micropump transition charge) was measured at $3.12 \mu$ As. Oscilloscope was configured to measure the product of voltage and current and produce the micropump power (trace P, Figure 7). Although the micropump power peaks at approx. $16 \mathrm{~W}$ (Figure 7), its duration is only about $5 \mu \mathrm{s}$, therefore average power, delivered to the micropump in a half-period, is only 1.6 mW.

2.) A "minimum drive" condition on the other hand sets only $200 \mu$ s of driving time. Note that the dead-time (DT) during "minimum drive" condition is depending on the driving signal period (DT $=\mathrm{T} / 2-200 \mu \mathrm{s}$ ). Time difference of $200 \mu \mathrm{s}$ was selected to accommodate optocoupler on/off switching times and analog-to-digital converter conversion time in order to avoid shorting both optocouplers. Figure 8 shows the micropump "minimum drive" output signal of initial prototype at $100 \mathrm{~Hz}, \pm 100 \mathrm{~V}$ amplitude. After initial driving with amplitude $\pm 98 \mathrm{~V}$ for $200 \mu$ s (flat $\mathrm{max} / \mathrm{min}$ part, Figure 8), the piezoelectric actuator voltage decays as an RC discharge down to $50 \mathrm{~V}$. The decay RC time constant is independent of voltage polarity, but depends on the pumped media viscosity for particular pump construction.

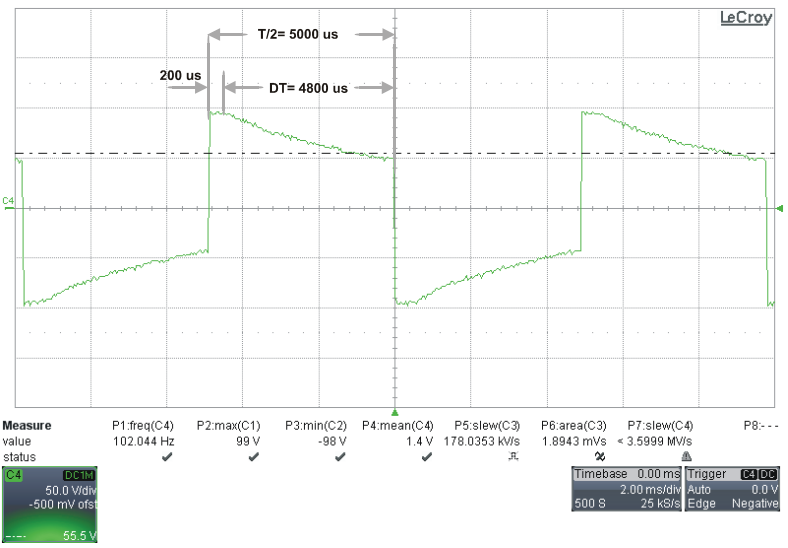

Figure 8: Initial prototype "minimum drive" micropump signal.

Micropump frequency was swept in the range from $50 \mathrm{~Hz}$ to $1 \mathrm{kHz}$ in both "full drive" and "minimum drive" modes. Excel control software was set to maximum piezoelectric actuator voltage of $125 \mathrm{~V}$. Actual positive and negative driving signal amplitudes, slew rates and power consumption were measured at each micropump frequency setting. Micropump amplitude vs. excitation frequency results are presented in Figure 9.

Micropump driving signal voltages were limited to $\pm 125 \mathrm{~V}$ due to piezoelectric actuator limitations. In the low-frequency range (i.e. around $100 \mathrm{~Hz}$ ), actual amplitudes of $\pm 100 \mathrm{~V}$ were achieved.

Module current consumption $I_{c c}$ is presented in Figure 10. At the target operating frequency of $100 \mathrm{~Hz}$, in 


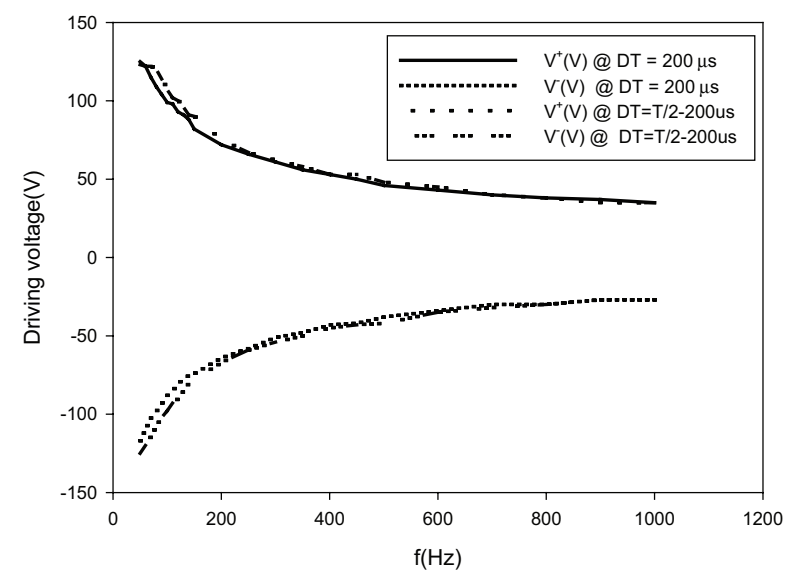

Figure 9: Voltage -frequency sweep of the initial prototype.

"full drive" mode with $\mathrm{SR}^{+}=\mathrm{SR}^{-}=11 \mathrm{~V} / \mu \mathrm{S}$, module current consumption was $108 \mathrm{~mA}$, afterwards the current consumption levels out. The majority of current consumption is attributed to high-voltage power supplies, which enter saturation, whenever their PWM duty cycle is clamped to a maximum value. Full driving voltage regulation frequency range can only be achieved up to a point, where actual voltage level becomes less than desired value. According to Figure 9, maximum piezoelectric voltage of $125 \mathrm{~V}$ can be set only in the range up to $70 \mathrm{~Hz}$. Afterwards, due to increased output load, both high voltage power supplies achieve maximum admissible PWM duty cycle, resulting in ever lower actual driving voltage.

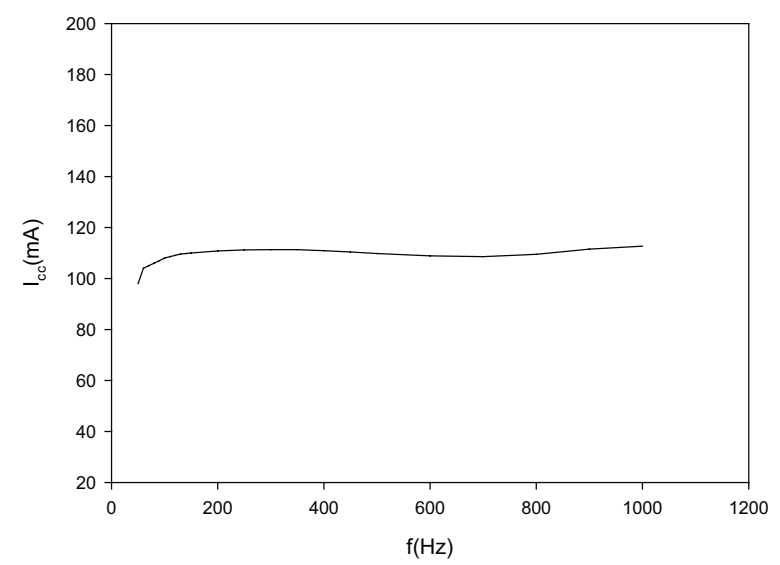

Figure 10: Current consumption of the initial prototype.

Figure 11 is showing positive and negative slew rate ( $\mathrm{SR}^{+}$and $\mathrm{SR}^{-}$, respectively), which were the most promising improvements in driving signal.

In comparison with our previous micropump driver designs $[4,5]$, which achieved typical slew rates of $200 \mathrm{~V} /$

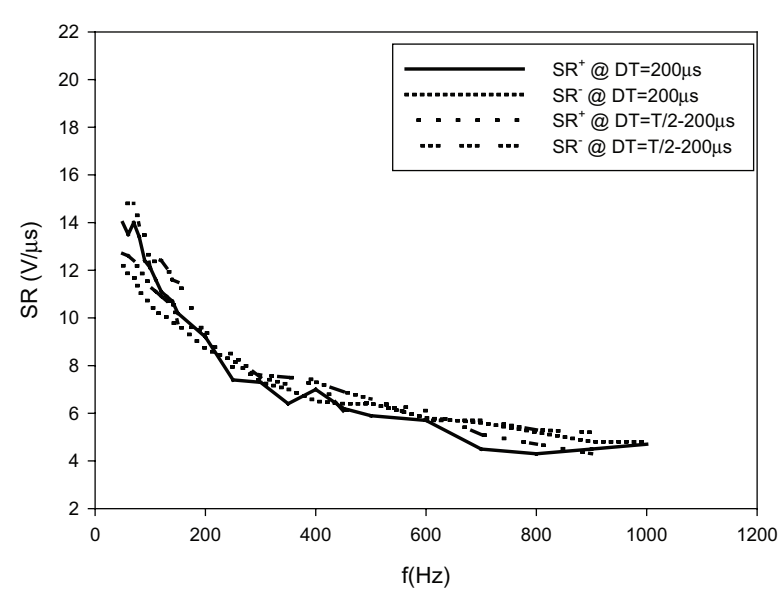

Figure 11: Positive and negative slew rate vs. frequency of the initial prototype.

$m s$, presented initial prototype exhibited slew rates in order of several $\mathrm{V} / \mu \mathrm{s}$. Frequency dependent decrease of both slew rates $(\Delta V / \Delta t)$ is directly related to a decrease of driving voltage $\left(\Delta \mathrm{V}=\mathrm{V}^{+}-\mathrm{V}\right)$, as shown in Figure 9. Although presented initial prototype exhibited a significant improvement in terms of slew-rate, it still failed to achieve maximum admissible driving signal amplitude of $\pm 125 \mathrm{~V} @ 100 \mathrm{~Hz}$.

\section{Module improvement}

In order to improve the micropump driving signal, power supply voltage regulation range would have to be extended over micropump excitation frequency. To achieve this, output voltage levels would have to be regulated at a lower PWM duty cycle setting on both high-voltage power supplies. First limitation in this process is the selected MOSFET on-resistance (typ. $4 \Omega$, for TN2404), which together with turn-on delay time (10 $\mathrm{ns}, \mathrm{TN2404}$ ) set the boost SMPS inductance range in order of $\mathrm{mH}$, so output voltages in between 100 and 150 $\mathrm{V}$ can be achieved. Furthermore, the series resistance of applied inductor (Bourns, SRR0603, L1 and L2 on Figure 2 ) is typically $8 \Omega$ and its maximum admissible DC current $200 \mathrm{~mA}$. In our case, we limited the selection of transistor housings to SOT-23, to minimize the size of entire module. Consequentially abovelisted design limitations narrow the options only to an increase in SMPS input power supply voltage $\left(\mathrm{V}_{\mathrm{PWR}^{\prime}}\right.$ Figure 2$)$ from $5 \mathrm{~V}$ to $9 \mathrm{~V}$. Microcontroller operates from a $5 \mathrm{~V}$ power supply, which was provided by additional linear regulator (MCP1703CB). Another modification was to use a dual power MOSFET driver (TC4427) as a voltage-level translator between $5 \mathrm{~V}$ PWM microcontroller outputs (OC1A/OC1B) and $9 \mathrm{~V}$ input power supply. Rectifying capacitors (C1, C3 Figure 2) were reduced from $100 \mu \mathrm{F}$ 
to $47 \mu \mathrm{F} / 100 \mathrm{~V}$, which are available in $\Phi=6 \mathrm{~mm}$ footprint. As with initial prototype, the measurements were repeated under same conditions, only this time a $9 \mathrm{~V}$ power supply was used. Micropump amplitude vs. excitation frequency results are presented in Figure 12.

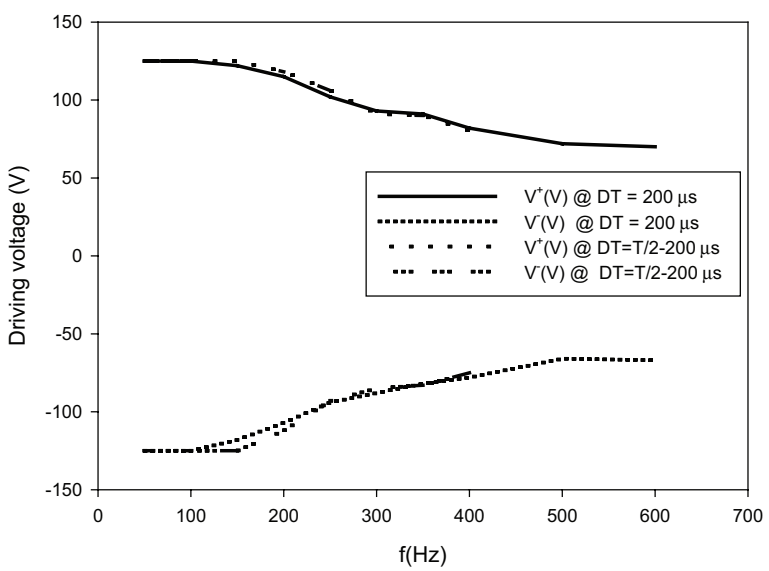

Figure 12: Voltage -frequency sweep of the improved prototype.

In low-frequency range, micropump driving signal reached admissible voltage limit of $\pm 125 \mathrm{~V}$. In comparison to the voltage scan of the initial prototype, the clamping interval extended from $70 \mathrm{~Hz}$ to $150 \mathrm{~Hz}$. Such an improvement in driving signal amplitudes comes at a cost of an increased module current consumption $I_{C C}$ which is presented in Figure 13.

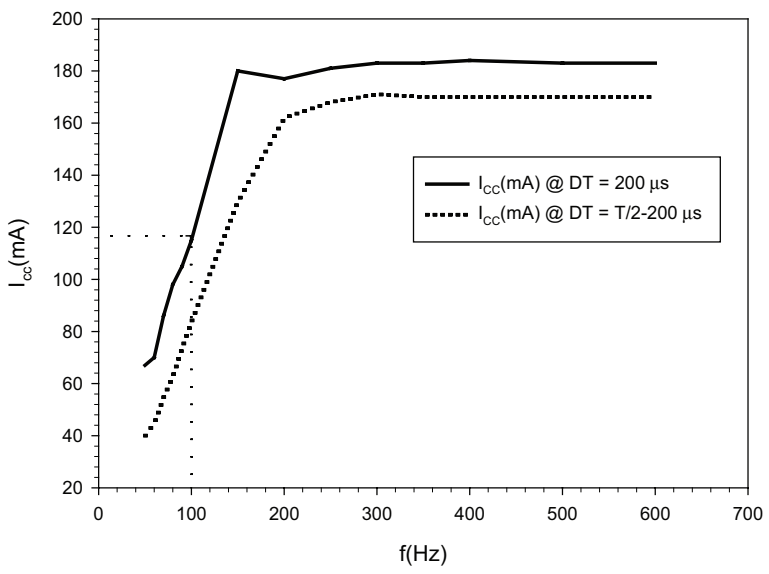

Figure 13: Current consumption of the improved prototype.

At the target operating frequency of $100 \mathrm{~Hz}$, in "full drive" mode with $\mathrm{SR}^{+}=\mathrm{SR}^{-}=16 \mathrm{~V} / \mu \mathrm{s}$, module current consumption was clamped to $118 \mathrm{~mA}$, at $150 \mathrm{~Hz}$ the current consumption levels out to $180 \mathrm{~mA}$. In "minimum drive" mode, the current consumption levels out at $170 \mathrm{~mA}$. Due to $10 \mathrm{~mA}$ difference between "full" and "minimum" driving mode, the majority of current consumption is attributed to design of SMPS boost converters. Current consumption of $180 \mathrm{~mA}$ could be marginally extended to $200 \mathrm{~mA}$ due to SRR0603 inductance limitation. This was achieved by rising the power supply value from $9 \mathrm{~V}$ to $10.5 \mathrm{~V}$. After that point, at $11 \mathrm{~V}$, the switching optocouplers power dissipation limitation $(150 \mathrm{~mW})$ is exceeded.

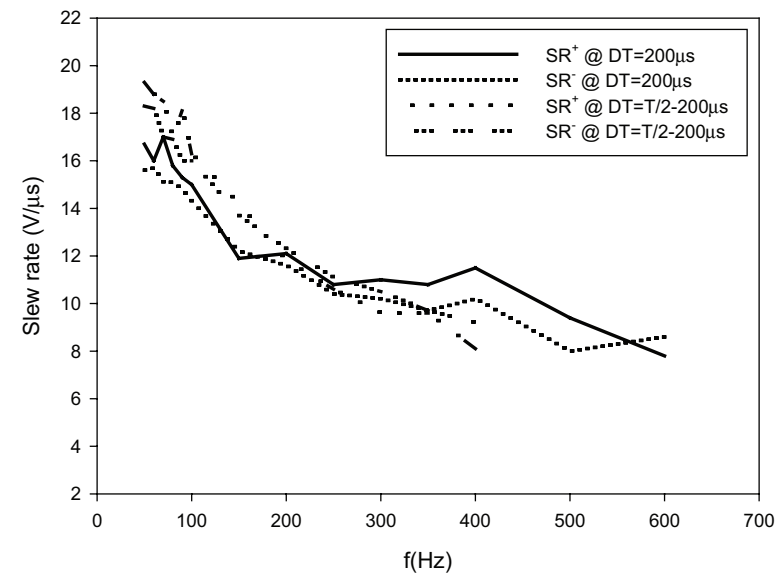

Figure 14: Positive and negative slew rate vs. frequency of the improved prototype.

Due to extended operation at maximum driving amplitude of $\pm 125 \mathrm{~V}$, shown in Figure 12, both slew rates also improved from initial $11 \mathrm{~V} / \mu$ s to $16 \mathrm{~V} / \mu \mathrm{s}$ in "full drive" mode at $100 \mathrm{~Hz}$, as depicted in Figure 14. In "minimum drive" mode, this value is even higher ( $18 \mathrm{~V} / \mu \mathrm{s})$. More important is the fact, that this slew rate remains over $10 \mathrm{~V} / \mu$ s up to $400 \mathrm{~Hz}$, which enables testing of our microcylinder micropumps, with smaller $(\Phi=6 \mathrm{~mm})$ piezoelectric disc with capacitance of $4 \mathrm{nF}$. We also tested the ability for setting various slewrates using different optocoupler base resistances. This feature can be applied, when slew rate is to be changed during operation. Such instance occurs during pump starting process, where a trapped bubble in the pumping chamber has to be expelled or when flow control is coarse-adjusted by altering the slew rate (Figure 22).

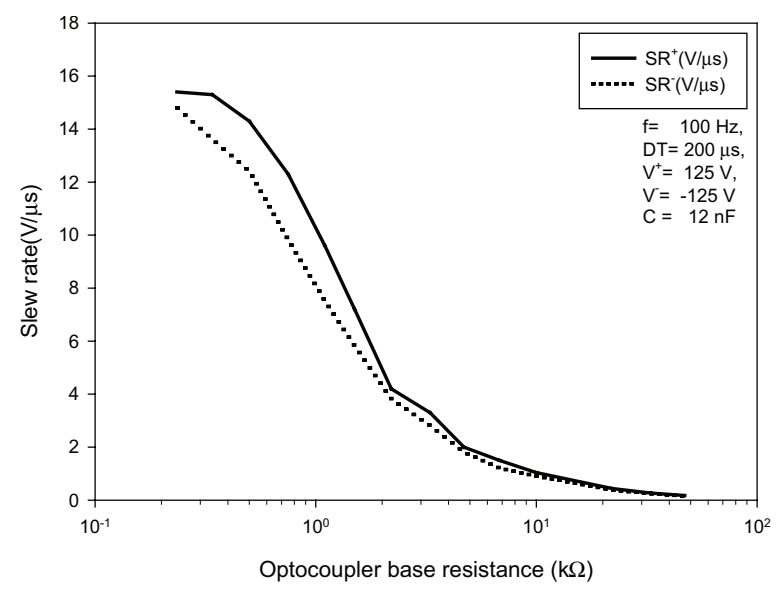

Figure 15: Driving signal slew-rates vs. optocoupler resistances. 
Again, micropump excitation frequency was set to 100 $\mathrm{Hz}$, with $\pm 125 \mathrm{~V}$ amplitude and the driving module was configured in the "full drive" mode. Module current consumption was evaluated against slew rate. According to Figure 13 in "full drive" mode (dashed line), with $100 \mathrm{~Hz}$ and both slew-rates set to $16 \mathrm{~V} / \mu \mathrm{s}$, the module current consumption is $118 \mathrm{~mA}$. Both slew rates and area measurements were calculated on-the-fly by the oscilloscope. Optocoupler base resistance was limited to $220 \Omega$ due to microcontroller output driving capability. On the other hand, upper base resistance limit was set by driving signal shape. Whenever slew-rate fell below $1 \mathrm{~V} / \mu \mathrm{s}$, resulting signal became sinewave-flanked.

Module current consumption, shown in Figure 16, remains practically independent (125 mA in "full drive" mode) of slew-rate just to the point, where the slew-rate falls under $1 \mathrm{~V} / \mu \mathrm{s}$. An increase in current consumptions in "full drive" mode can be attributed to measurement error, since average current measurements at high slew rates are hard to establish, due to constantly changing SMPS duty cycle. Such a discrepancy could be rectified using a larger output capacitor. The majority of current consumption is attributed to both SMPS power sources. In "minimum drive" mode, the current consumption is reduced to $70 \mathrm{~mA}$. Such "minimum drive" mode consequentially enables power-saving feature during operation with reduced flow. On the other hand, "full drive" mode with its high slew-rate improves the micropump purging (air pumping) capability.

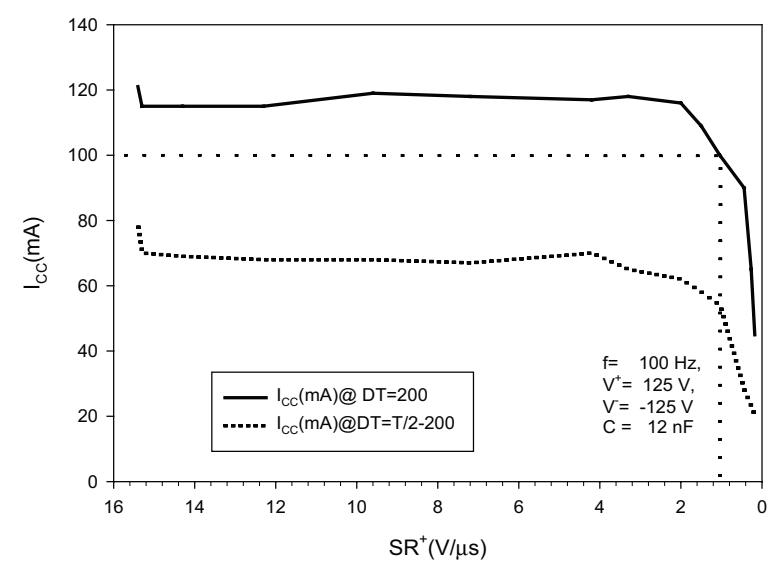

Figure 16: Power consumption vs. positive slew-rate.

Performed set of measurements was also repeated on our microcylinder micropump which uses a smaller piezoelectric disc with capacitance of $4 \mathrm{nF}$. Compared to $12 \mathrm{nF}$ microcylinder micropump, the limit voltage (125 V) regulation area extended to $400 \mathrm{~Hz}$. Both slew rates improved even more, reaching the levels of $22 \mathrm{~V} / \mu \mathrm{s}$ in "full drive". Likewise, the current consumption in both modes, compared to Figure 13, reduced only slightly - $175 \mathrm{~mA}$ in "full drive" and $160 \mathrm{~mA}$ in "minimum drive" mode.

\section{Fluidic characterization}

After the initial micropump driver testing, the system for computer controlled characterization of piezoelectric micropumps was set up (Figure 17). Analyzed driving module was connected to tested microcylinder pump. DI water filled tank was connected on micropump input and pressure/flow evaluation equipment on its output.

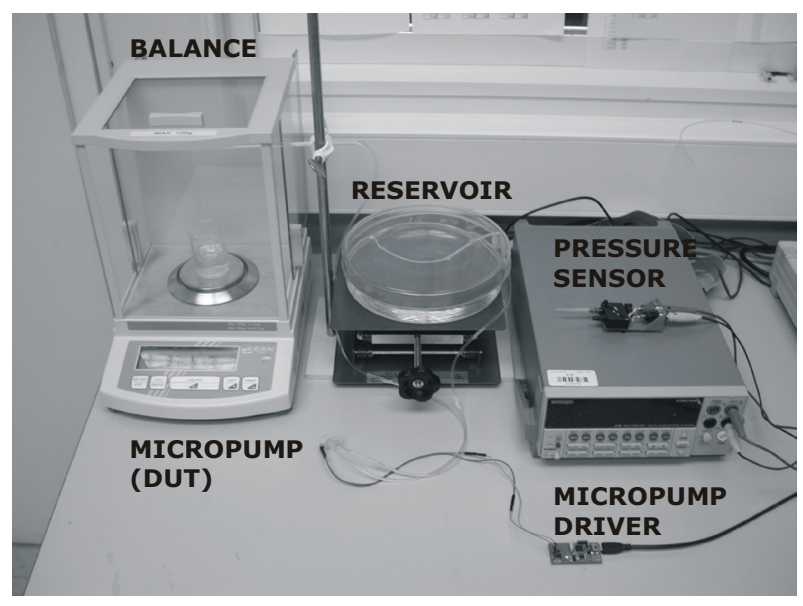

Figure 17: Measurement setup.

Micropump flow rate was measured using a Kern $A B J$ 120-4M precision balance. Presented micropump driving module was compared to previous driving modules, designed in our Laboratory [5]. These versions produce a rectangular signal with $\mathrm{RC}$ charge/discharge front and rear edge transitions (RC asymmetric driver). Our previous research of micropump performance on signal shape [6] has demonstrated better micropump flow and backpressure performance, when positive and negative voltage of RC signal are made symmetric (RC symmetric driver).

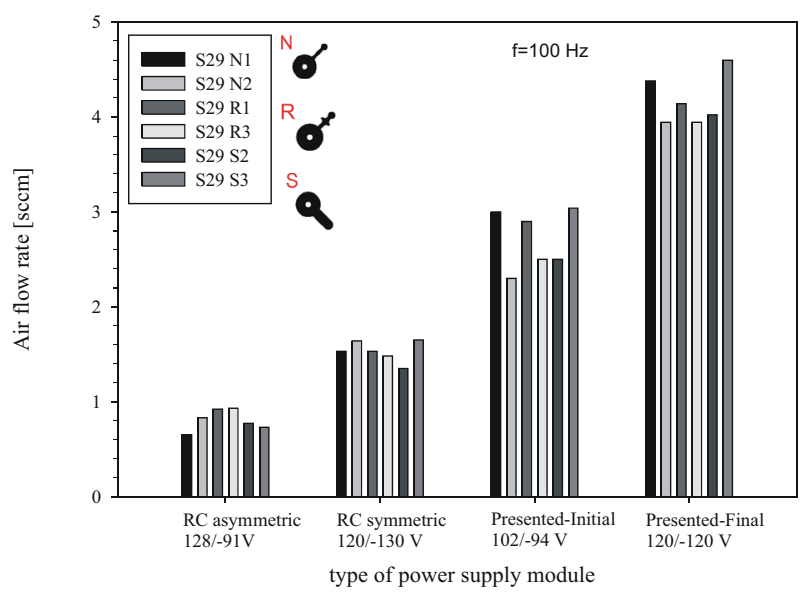

Figure 18: Air flow comparison of developed micropump driving modules. 
Three distinct micropump designs (N, R, S), each with different outlet channel geometry, were compared using RC asymmetric/symmetric driver and both initial and final version of the presented driver. Air flow rate (Figure 18) and DI water flow rate (Figure 19) measurements were performed at $100 \mathrm{~Hz}$, while the presented driver was configured in "full-drive" mode in both initial and final version.

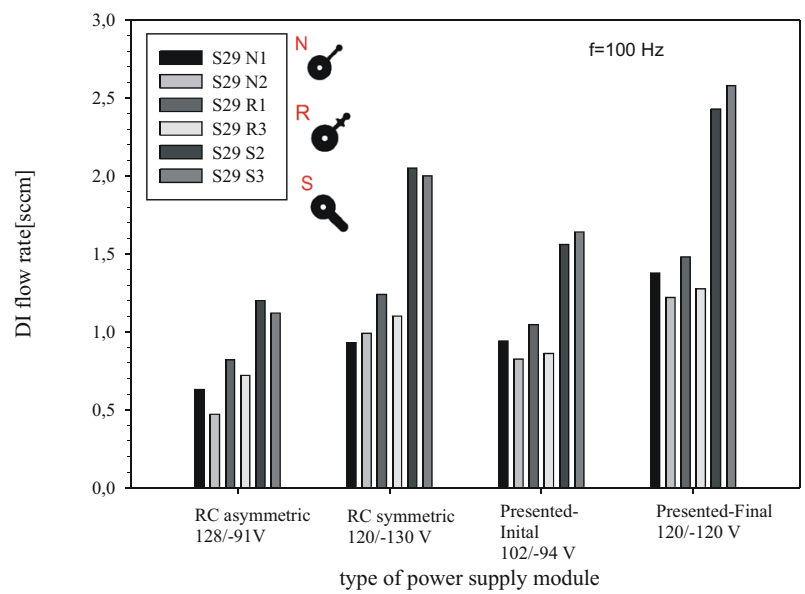

Figure 19: DI water flow comparison of developed micropump driving modules.

While both presented driver versions perform significantly better than previous ones, especially final version of presented driver dominates the air pumping, where it significantly increases the air flow rate (from $1.6 \mathrm{sccm}$ to $4.2 \mathrm{sccm}$ ) in comparison with symmetric RC driver.

Compared with symmetric and asymmetric versions of RC-like driver, presented driver surpasses all previous performances. Flow rate increase for DI water from 2.2 sccm to $2.6 \mathrm{sccm}$ is not so substantial.

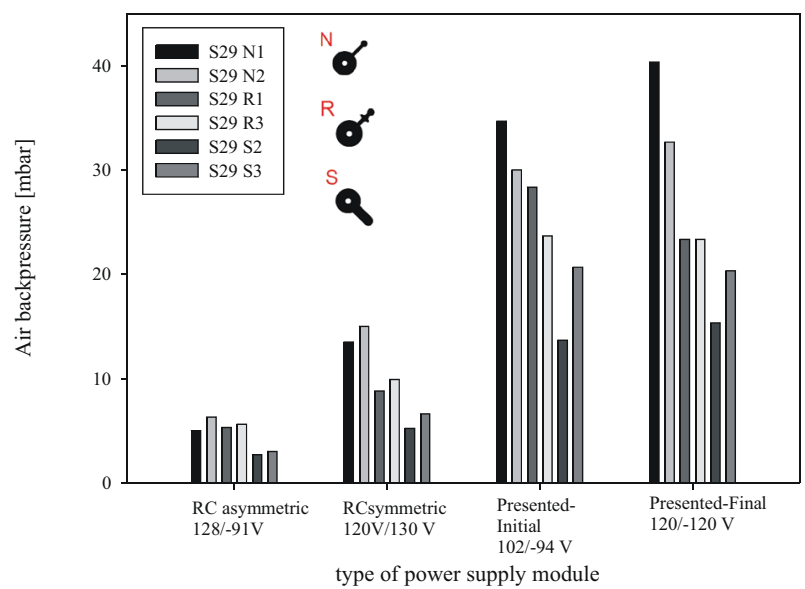

Figure 20: Air backpressure comparison of developed micropump drivers.
Both versions of presented driver almost doubled air backpressure performance, compared to both RC type drivers (see Figure 20). Final driver version is achieving its peak value of 39 mbar on N1 type micropump in "full drive" mode.

Final version of presented driver improved DI water backpressure of initial version by $30 \%$, achieving its peak value of 240 mbar on $\mathrm{N} 1$ type micropump (see Figure 21). Both presented versions improved DI water backpressure performance over RC-type drivers.

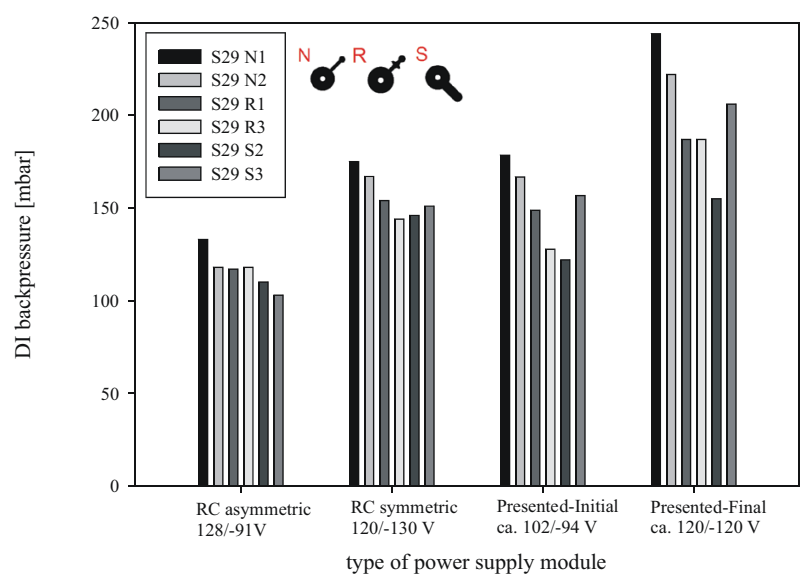

Figure 21: DI water backpressure comparison of developed micropump drivers.

Final version of presented driver was configured in "full drive" mode and amplitudes were set at $\pm 105 \mathrm{~V}$ at 100 $\mathrm{Hz}$ using the micropump S29R1. DI water and air flow rate were measured, while both slew-rate values were adjusted. Results in Figure 22 show that flow rate in both cases is practically independent of slew-rate (only $\mathrm{SR}^{+}$displayed). Backpressure characteristics, depicted in Figure 23, deteriorate with slew rate less than $4 \mathrm{~V} / \mu \mathrm{s}$. If slew-rate is lowered down to $1 \mathrm{~V} / \mu \mathrm{s}$, maximum flow rate can be achieved, with reduced power consumption to $100 \mathrm{~mA}$ (see Figure 16). Even with slew rate

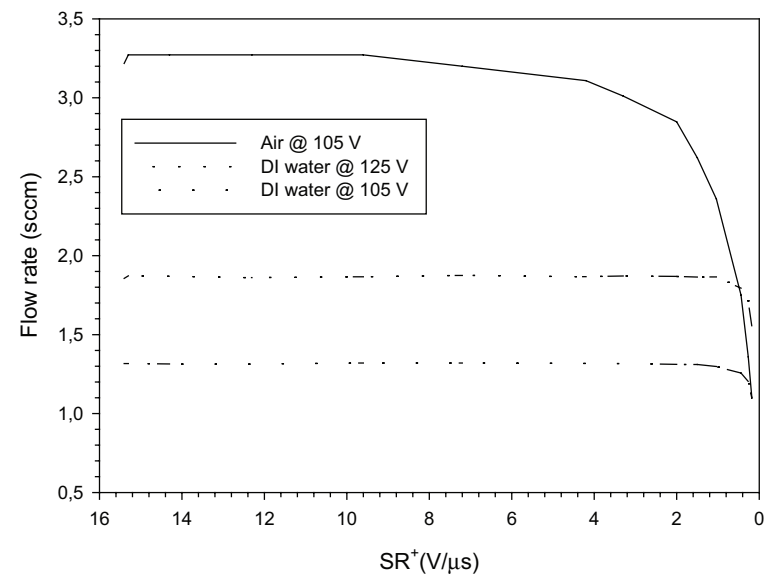

Figure 22: Flow rate vs. slew rate in "full drive" mode. 
kept at $1 \mathrm{~V} / \mu \mathrm{s}$, resulting flow rate is significantly larger compared to our previous RC driving modules, which achieved slew rates of $200 \mathrm{~V} / \mathrm{ms}$. Power consumption can be further reduced using "minimum drive" mode.

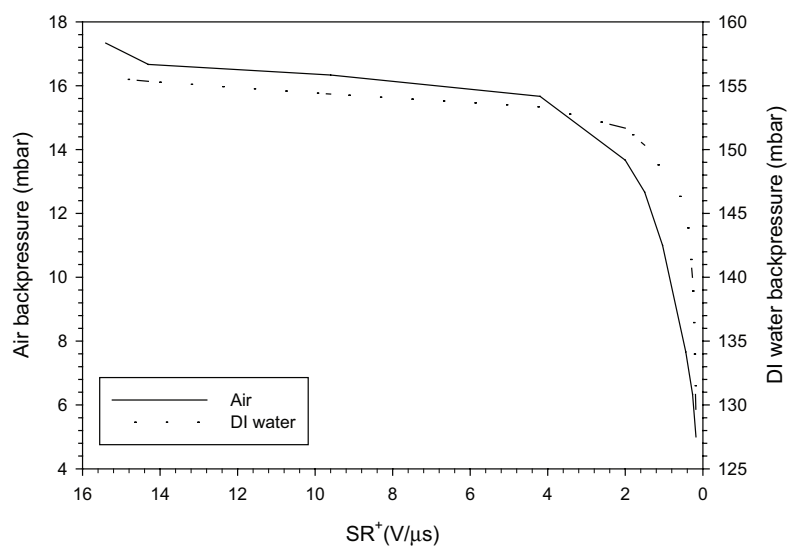

Figure 23: Backpressure vs. slew-rate in "full drive" mode.

Despite the fact, that keeping slew-rate in range of 16 $\mathrm{V} / \mu \mathrm{s}$ has no significant influence on flow rate and backpressure characteristics, we believe that higher slewrate improves other micropump characteristics such as self-priming and bubble tolerance and makes the micropump operation more reliable in different operating conditions.

\section{Conclusion}

Design and characterization of an advanced piezoelectric micropump driver with programmable slew-rate and dead-time for driving custom made piezoelectric micropumps was presented. Developed driver enables independent setting of several rectangular output signal parameters, such as frequency, positive and negative amplitude, slew-rates, dead time, and modes of operation (pump/valve).

Driving signal frequency range from several $\mathrm{Hz}$ to 1 $\mathrm{kHz}$ was investigated. Amplitudes up to $250 \mathrm{~V}_{\mathrm{pp}}$ were achieved in lower frequency range (up to $150 \mathrm{~Hz}$ ). In this lower frequency range, positive and negative signal slew-rates up to $18 \mathrm{~V} / \mu$ s were achieved. Optimal micropump actuation frequency range from 50 to $400 \mathrm{~Hz}$ was found using DI water. In comparison with our previous driver designs with $\mathrm{RC}$ charge/discharge signal shape, presented version increases air flow capability of micropumps from $1.6 \mathrm{sccm}$ to $4.2 \mathrm{sccm}$. Maximum module power consumption was 1.6 W (180 mA @ 9 V). Presented module is capable of driving a $200 \mu \mathrm{m}$ thick piezoelectric actuator with a capacitance in order of several nF. Small size of ( $25 \mathrm{~mm}$ x $25 \mathrm{~mm} \times 5 \mathrm{~mm}$ ) makes presented driver suitable for integration inside micropump housing.

In order to further investigate the impact of slew-rate on micropump reliability, other characteristics, such as self-priming and bubble-tolerance, should be measured.

\section{Acknowledgements}

This work was performed within the framework of a project supported by the Slovenian industrial partner KOLEKTOR Group and the Ministry of Education, Science, Culture and Sport (Grant No P2-0244).

\section{References}

1. "Bartels mp-x Controller", http://www.bartelsmikrotechnik.de/index.php/produkte/elektronik, [Accessed: 18. 7. 2019],

2. "Bartels mp6-OEM Controller", http://www.bartels-mikrotechnik.de/index.php/produkte/elektronik, [Accessed: 18. 7. 2019],

3. C. Chao, P. Huang, M. Chen, L. Jang, »Design and analysis of charge-recovery driving circuits for portable peristaltic micropumps with piezoelectric actuators Sensors and actuators. A, Physical, 2011, vol. 168, pp. 313-319, https://doi.org/10.1016/j.sna.2011.04.027

4. M. Antonijevič, T. Dolžan, B. Pečar, U. Aljančič, M. Možek, D. Vrtačnik, D. Resnik, S. Amon, "Characterization system for piezoelectric micropumps", in Conference 2012 proceedings $48^{\text {th }}$ International Conference on Microelectronics, Devices and Materials \& the Workshop on Ceramic Microsystems, September 19 -September 21, 2012, Otočec, Slovenia. Ljubljana: MIDEM - Society for Microelectronics, Electronic Components and Materials, pp. 357362,

5. M. Možek, B. Pečar, U. Aljančič, D. Resnik, D. Vrtačnik, "Low-power piezoelectric micropump driving module", in Conference 2017 proceedings $153^{\text {rd }}$ International Conference on Microelectronics, Devices and Materials \& the Workshop on Materials for Energy Conversion and their Applications: Electrocalorics and Thermoelectrics, October 4 - October 6, 2017, pp. 157-162,

6. D. Resnik, B. Pečar, M. Možek, N. Lokar, D. Vrtačnik, Analyses of micropump performances under rigorous operating conditions. Conference proceedings 2018, in Conference 2018 proceedings $54^{\text {th }}$ International Conference on Microelectronics, Devices and Materials \& the Workshop on Sensors and Transdu- 
cers, October 3 - October 5, 2018, pp. 49-52,

7. T. Dolžan, B. Pečar, M. Možek, D. Resnik, D. Vrtačnik, "Self-priming bubble tolerant microcylinder pump«. Sensors and actuators. A, Physical, 2015, vol. 233, pp. 548-556,

http://dx.doi.org/10.1016/j.sna.2015.07.015

8. LTSPICE, Linear Technologies: http://ltspice.linear -tech.com/software/LTspiceXVII.exe, 16.7.2019

9. 8-bit AVR Microcontroller ATtiny102 / ATtiny104 Datasheet complete: http://ww1.microchip.com/ downloads/en/devicedoc/atmel-42505-8-bit-avrmicrocontrollers-attiny102-attiny104_datasheet. pdf, [Accessed: 15. 7. 2019]

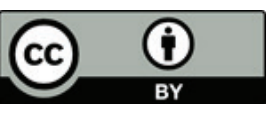

Copyright $\odot 2019$ by the Authors. This is an open access article distributed under the Creative Commons Attribution (CC BY) License (https://creativecommons.org/licenses/by/4.0/), which permits unrestricted use, distribution, and reproduction in any medium, provided the original work is properly cited.

Arrived: 25. 07. 2019

Accepted: 02. 09. 2019 